\title{
ФАКТОРЫ ВЗАИМОСВЯЗИ И ВЗАИМОВЛИЯНИЯ ЧЕЛОВЕЧЕСКОГО КАПИТАЛА И ТРУДОВОГО ПОТЕНЦИАЛА
}

\author{
(c) 2021 Мингазова Альбина Фаридовна \\ аспирант \\ Казанский (Приволжский) федеральный университет, Россия, Казань \\ E-mail: albina120587@mail.ru
}

В современной цифровой экономике исключительную роль играет человек с его знаниями, навыками, социальным опытом и творческими способностями. Данное объективное явление нашло адекватное отражение в экономической теории. В последние десятилетия развивается теория человеческого капитала. Формирование человеческого капитала происходит в течение всей жизни человека, зависит как от внутренних, так и внешних инвестиций. Внутренние инвестиции человек формирует путем развития навыков, получения знания, они приобретаются, в основном, в школе, в молодом возрасте и помогают реализоваться в течении всей жизни. Внешние инвестиции представляют вклад государства, работодателя для осуществления политических и экономических нужд. Наиболее активное использование накопленных навыков осуществляется в процессе трудовой активности. Поэтому приобретение новых знаний личности актуально для предприятий. Знания приобретаются путем формальной и неформальной подготовки. Повышение квалификации осуществляется благодаря инвестированию предприятия в переподготовку работника. В результате накапливаются знания и навыки, инновационные разработки, патенты, востребованные и актуальные для фирмы и общества в целом.

Ключевые слова: человеческий капитал, трудовой потенциал, инновации, знания, навыки, факторы производства.

Тезис о ведущей роли капитала в экономическом прогрессе провозглашается в разнообразных моделях экономического роста и подтверждается результатами многочисленных исследований российской и зарубежной практики.

Человеческий капитал - это коллективный ресурс, который возникает из знаний, навыков и способностей сотрудников. Л. Троу утверждает, роль концепции человеческого капитала является главенствующей в экономическом анализе, а М.Боуман считает, что человеческий капитал стал открытием и революцией в экономической мысли [7]. Принципиальные идеи теории человеческого капитала высказывались еще XVIIXVIII веках. Бурно развитие данная теория получила только со второй половины предыдущего столетия. Развитие концепции теории человеческого капитала получила благодаря экономистам Т.В.Шульц и Г.Беккер, которые получили Нобелевскую премию [28].

Наибольший вклад в развитие теории человеческого капитала внесли такие исследователи, как М.Блауг, М.Гроссман, Дж. Минцер, М.Перлмен, Л.Туроу, Ф, Уэлч, Б. Чизуик и др. Возник- новение теории человеческого капитала было продиктовано необходимостью понимания природы высокой доли изменений совокупного выпуска, не обусловленной количественным приростом задействованных факторов производства - труда и капитала, а также невозможностью универсальной трактовки феномена неравенства доходов на основе существовавшего концептуального аппарата. Поиск ответов на эти вопросы привел к пониманию характера рабочей силы как совокупности естественных и приобретенных качеств, дифференцирующих производительный потенциал индивидов. Главным в данной концепции является то, что получаемые индивидами знания и навыки приобретают на рынке труда конкретную определенную ценность.

В основе теории человеческого капитала рассматривается поведение человека и его влияние на экономический процесс, который представляет принцип поведения личности как индивида, и включает рациональное поведение. Что определяет базу экономического подхода рациональных ожиданий, согласно которым индивид при определении решения, приносит 
выгоду или полезность для экономической целесообразности.

Согласно теории Г.Беккера в понятие «человеческий капитал» должна вкладываться как материальная, так и духовная составляющая. Беккер считает, что человеческий, физический и финансовый капиталы представляют различные аспекты, однако их взаимосвязь прослеживается тем фактом, что человека нельзя отделить от его навыков, здоровья и ценностей. Исходя из этого человеческим капиталом обладают практически все социально-адаптированные члены общества.

В доиндустриальном обществе приоритетом было взаимосвязь человека и природы, где земля является основным фактором производства. В индустриальной эпохе - воздействие человека с преобразованной природой, где капиталу отводится главенствующая роль, постиндустриальный мир представляет из себя взаимодействие между людьми и подразумевает квалифицированный труд [22].

Приведем определение понятия человеческого капитала российскими исследователями в таблице 1.
Обобщая указанные определения можно дать следующее определение человеческому капиталу. Человеческий капитал представляет собой важный ресурс для создания ценности. Определяется человеческий капитал как совокупный капитал, связанный с затратами на жизнь, образование и профессиональный опыт. Влияет на экономическое и глобальное развитие и меняется со временем.

Саморазвитие и развитие человеческого капитала в сфере производства должны осуществляться за счёт мотивации высококвалифицированного производительного труда, который применяется в процессе инновационного технологического развития.

Экономическая категория присуща человеческому капиталу, когда работник реализует свой капитал для работодателя, в обмен за вознаграждение [1].

Маршалл подчеркивал, что производство основывается на двух факторах: человек и природа [37].

Человеческий капитал - главный фактор производства, который является объектом ис-

Таблица 1. Определение понятия человеческого капитала российскими учеными

\begin{tabular}{|c|c|}
\hline Автор определения & Определение понятия человеческого капитала \\
\hline Б.М. Генкин & $\begin{array}{l}\text { Определяет человеческий капитал как набор качеств влияющих на источник } \\
\text { доходов для человека и влияющих на производительность [3]. }\end{array}$ \\
\hline $\begin{array}{l}\text { А.Н. Добрынин } \\
\text { и С.А.Дятлов }\end{array}$ & $\begin{array}{l}\text { Человек в качестве ведущего, общественного и творческого фактора в рыночной } \\
\text { экономики, влияющий на проявление производительных сил [6]. }\end{array}$ \\
\hline С.М. Климов & Человеческие способности, которые напрямую влияют на доход [9]. \\
\hline И.Т. Корогодин & $\begin{array}{l}\text { Различные навыки, приобретенные знания и улучшенные в течение всей жизни, } \\
\text { благодаря инвестициям и влияющие на производительность труда [10]. }\end{array}$ \\
\hline В.Н. Костюк & $\begin{array}{l}\text { Способность человека, которая помогает ориентироваться в неопределенном } \\
\text { моменте [11]. }\end{array}$ \\
\hline А.С. Лифшиц & Качества приносящие доход государству, предприятию и человеку [13]. \\
\hline И.А. Никитина & $\begin{array}{l}\text { Полностью реализованный человеческий потенциал, т.е. данные накопленные в } \\
\text { период инвестирования в себя и применённые в течении всей жизни [8]. }\end{array}$ \\
\hline Автор определения & Определение понятия человеческого капитала \\
\hline К.В.Гуменников & $\begin{array}{l}\text { - то, чем обладает человек, } \\
\text { - доход, } \\
\text { - ресурс предприятия для получения прибыли [5] }\end{array}$ \\
\hline Л.И. Абалкина & $\begin{array}{l}\text { рассматривает человеческий капитал как сумму врожденных способностей, } \\
\text { общего и специального образования, приобретенного профессионального опыта, } \\
\text { творческого потенциала, морально-психологического и физического здоровья, } \\
\text { мотивов деятельности, обеспечивающих возможность приносить доход [19] }\end{array}$ \\
\hline Т.Г. Мясоедова & $\begin{array}{l}\text { Общие природные способности, физические, нравственные, мотивирующие } \\
\text { ценности, которые соблюдаются нормами и правилами человеческого поведения } \\
\text { [16]. }\end{array}$ \\
\hline М.М. Критский & $\begin{array}{l}\text { «авансированный человеческий капитал - это подготовка к производственной } \\
\text { деятельности изначально [12]. }\end{array}$ \\
\hline $\begin{array}{l}\text { Ф.В. Стукач, Е.Ю.Лалова, } \\
\text { И.В.Ильинский [8] }\end{array}$ & $\begin{array}{l}\text { Основной и развитый, основной будет применяться на производстве, развитый } \\
\text { это накопленные навыки и знания к началу производственной деятельности [23]. }\end{array}$ \\
\hline
\end{tabular}


следования в системе управления персоналом. Исследования в области управления сосредоточены на различных характеристиках, которые влияют на инновационное поведение. По формам выражения он может быть как внешним, так и внутренним, по источникам происхождения - наследственный, врождённый, приобретенный, трудовой и т.д. Трудовой потенциал важный ресурс для стимулирования инноваций. Для конкурентного преимущества предприятия, основой является квалифицированные работники. Квалифицированные работники играют значимую роль в объедении, интеграции и преобразовании внешних знаний со знаниями, генерирующими внутри фирмы, тем самым расширяя границы инновационной деятельности.

Человеческий капитал в современной экономике является основой для построения современной инновационной экономики. Конкурентоспособность организации зависит от профессионализма сотрудников.

Мустафин в своем исследовании, отмечает что инновационный потенциал влияет на конкурентоспособность. А фактор труда, выступающий в лице человеческого капитала, и есть инновационное развитие [15].

По концепции Всемирного банка, валовый внутренний продукт страны отражает текущее накопление и потребление, а значимая часть потребительских расходов на питание, образование, жилищные расходы, здравоохранение, и др. потребности населения отражает воспроизводство человеческого капитала. По исследовательским данным, в построении национального богатства доминирует человеческий капитал. К примеру, в США, Западной Европе он составляет 3/4 национального богатства [36].
Взаимосвязь трудового потенциала и человеческого капитала схематически представим на рисунке 1 .

Врожденные способности человека определяют человеческий потенциал. В результате материальных и нематериальных вложений, таких как обучение, воспитание, жизненных опыт, приобретенные навыки и умения образуется трудовой потенциал. Т.е. трудовой потенциал - это совокупность врожденных способностей человека, результатов его воспитания, особенностей характера, здоровья, интеллекта, физических особенностей и способностей, творчества, полученного образования, нравственности, социальной активности, приобретенных навыков и умений. Исходя из этого трудовой потенциал - реализованный человеческий потенциал. Чтобы реализовать свой трудовой потенциал человеку необходимы время, мотивация и труд. И тогда только получаем человеческий капитал, т.е. реализованный трудовой потенциал.

Трудовой потенциал имеет свою стоимость и, когда его стоимость начинает приносить новую стоимость, потенциал становится капиталом, т.к. капитал представляет собой «самовозрастающую стоимость».

Создание новой стоимости - критерий превращения потенциала в капитал, то есть человеческий капитал представляет собой реализованный трудовой потенциал. До того момента, пока трудовой потенциал не приносит доход, он не является капиталом. Как только появляется созданный им доход, потенциал становится капиталом, при этом не весь трудовой потенциал реализуется в человеческом капитале.

При всем этом трудовой потенциал является частью человеческого потенциала. Из всего

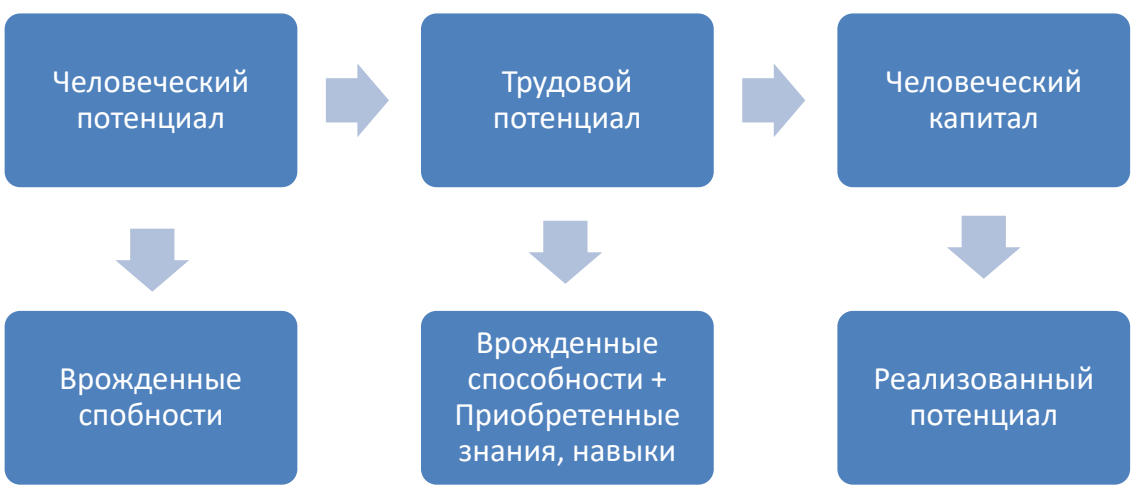

Puc. 1. Взаимосвязь трудового потенциала и человеческого капитала. Источник: составлено автором 
этого можно сделать вывод, что трудовой потенциал - это одна из долей человеческого потенциала, который частично реализуется в человеческом капитале. А человеческий капитал, таким образом, - это реализованный трудовой потенциал.

Под трудовым потенциалом следует понимать совокупную рабочую силу и совокупную общественную способность населения к труду [2]. Из данного определения следует, что трудовой потенциал включает в себя как качественную, так и количественную характеристики. Количественная характеристика предполагает изучение статистических данных по основным компонентам трудового потенциала. Качественная характеристика проистекает из сущности непосредственно самих компонентов трудового потенциала, таких как физическая составляющая (в частности, работоспособность, здоровье), квалификационный элемент (профессионализм, квалификация, уровень образования, компетентность, опыт и т.п.), психолого-личностная компонента (мотивации, личные качества, склонности, способность к творчеству и т.д.) [17]. Отсюда следует, что трудовой потенциал есть единство качественных и количественных характеристик формирующих его компонентов. При этом первостепенное значение для инновационного развития экономики страны имеет качественная составляющая, которая, однако, не может быть выражена без количественного сопровождения [27].

Формирование трудового потенциала - это длительный и очень сложный процесс, так как и каждый человек, и коллектив проходят индивидуальный путь познания и опыта. Формирование идет в следующих сферах:

- профессиональной деятельности непосредственно в организации;

- взаимоотношений в обществе;

- социальной сфере - вне организации.
В структуру трудового потенциала работника включают средства и предметы труда, что представлено на рисунке 2.

Субъект деятельности, человек, выполняет целесообразную деятельность и имеет потенциальную возможность ее осуществления, повышения эффективности.

Для развития трудового потенциала необходимы значительные затраты и различного рода ресурсы индивида и общества.

Б.М.Генкин приводит примеры качественных характеристик трудового потенциала: нравственность, здоровье и т.д. [4]

Здоровье является важным фактором трудового потенциала, и сохранить его составляет большую проблему. Здоровье - это право человека и один из основных элементов благосостояния общества. Здоровье общества является необходимым условием развития государства. Оно играет значительную роль в увеличении потенциала экономического роста и конкурентоспособности. Здоровье является необходимым условием трудоспособности.

Трудовые ресурсы являются одним из главных элементов инновационного потенциала, качество и эффективное использование которого во многом определяют результаты его инновационной деятельности. Все это требует особого рассмотрения вопросов, связанных с эффективным формированием и использованием трудовых ресурсов.

Таким образом, доминирующим фактором инновационного развития становиться не материальное накопление, а накопление способностей, здоровья, уровня физического развития, знания и др.

Мустафин отмечает, что человек участвующий в производственном процессе, можно разделить на его потребности, такие как биологические, социально-психологические и экономические. И для того что бы перейти к иннова-

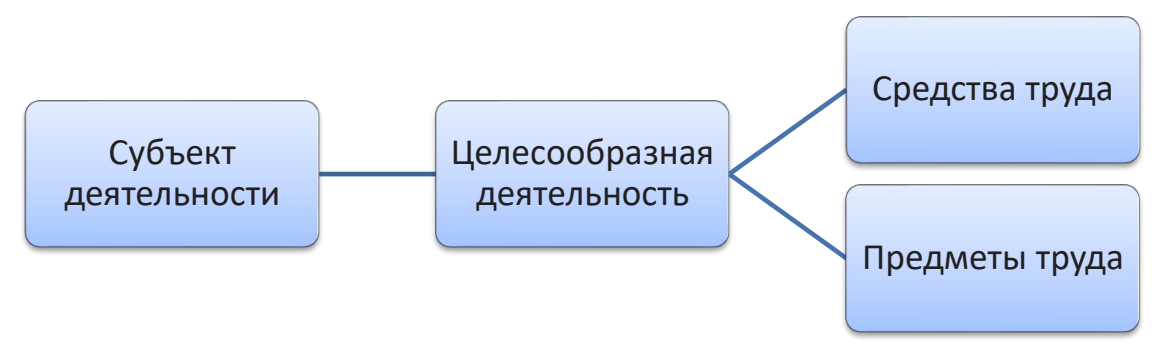

Puc. 2. Структура трудового потенциала работника как проявления целесообразной деятельности. Источник: составлено автором 
ционной экономике, нужно создавать не только новые технологии, но и развивать эффективную сферу управления человеческими ресурсами.

Таким образом, человеческий капитал - это коллективный ресурс, который возникает из знаний, навыков, и способностей человека. Например, обучение, помогает сотрудникам поддерживать современные навыки и позволяет им применять их в области инновации. Активное участие сотрудников в деятельности компании улучшает качество и использование человеческого капитала для инноваций.

Фирмы, как правило, используют свой трудовой потенциал по-разному. Менеджеры всегда сталкиваются с проблемой организации трудового потенциала и достижения инновационного успеха. В литературе способы, которыми фирмы управляют своими ресурсами для достижения эффективности и инноваций, изучены недостаточно [29]. Использование человеческого капитала важно для создания ценности, производительности. Например, управление сотрудниками с долгосрочной ориентацией, может способствовать повышению производительности компании, найма сотрудников на основе знаний, и дальнейшее их развитие, путем обучения и мотивации. Эти методы позволяют компаниям внедрять и реализовывать стратегию для развития инноваций. Этот фактор имеет значение, так как конкурентные преимущества человеческого капитала будут выявлены с помощью таких показателей деятельности, как инновации.

Рассмотрим факторы управления трудовым потенциалом фирм для реализации человеческого капитала:

Первым фактором является развитие человеческого капитала, путем управления трудовым потенциалом через обучение, ориентированное на выполнение задач, то есть «сверху - вниз»

Обучение сотрудников, ориентированное на выполнение заданий, положительно связано с инновациями компании. Во-первых, когда работники лучше подготовлены к получению, усвоению и применению знаний, связанную с задачами, способность компании увеличивается, что в свою очередь приводит к более совершенным инновациям на предприятиях [30]. Обучение конкретным предметным знаниям, способствует индивидуальному творческому мышлению, которое по мере накопления имеет тенденцию вносить вклад в инновации, и тем самым в человеческий капитал. Кроме того, об- учение, ориентированное на выполнении заданий, способствует эффективной координации между сотрудниками. Таким образом компании могут расширить область пересечения отдельных сотрудников и их знаний. Во-вторых, обучение, связанное с задачами, меняет распорядок работы в фирмах и повышает мотивацию сотрудников к инновациям. Специальное обучение ускоряет процесс, способствует реализации корпоративной политики и помогает инновациям использовать рыночные возможности. Обучение, связанное с конкретными задачами, не только обеспечивает передачу знаний, но также служит платформой для выработки общего понимания, того, каким образом невыявленные знания становятся общими, а сотрудники более рискованнее участвуют в создании инновации.

Вторым фактором является развитие человеческого капитала, путем управления трудовым потенциалом через участие сотрудников «снизу-вверх».

Использование стратегии «снизу-вверх» побуждает сотрудников выражать свое мнение, предложение по поводу рабочих вопросов и получать отзывы о своем вкладе от других сотрудников [32]. Руководители фирм могут поощрять действия сотрудников и их идеи. Например, Google поощряют сотрудников тратить значительную часть своего рабочего времени на собственные инициативы [33]. Целью этих действий является мотивация сотрудников к обмену идеями, предложениями, проблемами или мнениями по вопросам, связанным с работой для улучшения функционирования организации и воплощения их в инновации. Таким образом, участие сотрудников увеличивает поток и накопление знаний в организации. Работники ежедневно изучают подробности в технологиях, продуктах и рынках. Такое участие может выявлять ноу-хау, которыми обладают сотрудники, что способствует сбору знаний, и, следовательно, инновациям в фирмах. Поощрение свидетельствует о признательности и уважении фирмы к сотрудникам. Это мотивирует сотрудников к поиску новых знаний и укрепляет доверие и сотрудничество между фирмой и работниками, тем самым сотрудники могут брать на себя ответственность и инвестировать свой человеческий капитал. К примеру, сотрудники Nokia боялись предлагать изменения и рекомендации по улучшению технологических возможностей, что стало одним из важных факторов падения 
в период 2005-2010 годов [34]. Таким образом, участие сотрудников устанавливает нормы и механизмы, которые в свою очередь своевременно обеспечивают эффективную обратную связь с руководителями. Фирмы, которые мотивируют не только материальными вознаграждениями, обнаруживают, что признание ведет к успеху в разработке новых продуктов. Таким образом, участие сотрудников положительно связано с инновациями компании.

Третьим фактором является централизованное управление, в взаимодействие сотрудниками и в развитии человеческого капитала.

Фирмы значительно различаются между собой, с точки зрения, как высший менеджмент распределяет полномочия внутри организации, и как это влияет на развитие человеческого капитала. В компании с высоким уровнем централизации власти полномочия по принятию решений принадлежит только руководителям высшего звена, и сотрудники практически не участвуют в процессе принятия решений [35]. На организационные инновации влияет фактор мотивации сотрудников. Централизация полномочий помогает согласовать обучение, связанное с задачами. Во-первых, централизация полномочий может способствовать накоплению и развитию ресурсов- человеческого капитала и способностей сотрудников -через обучение, ориентированного на выполнении конкретных задач. В обучении, ориентированном на выполнение заданий, используется способность фирм в обработке информации и систематизировании ее в знания для достижения организационных целей. Во-вторых, топ-менеджмент в соответствии с мотивацией к инновациям организовывает задачи в повестке дня. Для планирования и внедрения задач формируются конкретные подсказки. Таким образом, задачи выполняются надлежащим образом. Предприятия, в лице топ-менеджеров, стимулируют сотрудников на поиск новых решений, новаторского подхода и применения знаний, тем самым развивая человеческий капитал. Но есть и отрицательный аспект, так как идеи, возникшие в результате восходящего процесса, необходимо оценивать и отбирать в течение длительных процедур, что снижает эффективность участия сотрудников. Идеи сотрудников с меньшей вероятностью бу- дут переданы на рассмотрение руководителям более высокого уровня. В централизованном управлении сотрудники меньше чувствуют ценность своего человеческого капитала, так как их предложения не рассматриваются моментально. Таким образом, возникает противоречие между участием сотрудников и централизованным управлением. Однако именно сотрудники владеют большей частью ресурсов фирмы и лучше всего могут предвидеть будущее развитии. Идеи, генерируемые работниками, могут систематически быть недооцененными менеджерами. Централизация власти в фирмах ослабляет взаимосвязь между трудовым потенциалом и человеческим капиталом.

Четвертым фактором в взаимосвязи трудового потенциала и человеческого капитала является экономическое благополучие. Сотрудники оптимистично настроены, если знают, что фирмы могут производить и продавать больше своей продукции и получать больше доходов. Непрерывные разработки производства, предоставляет сотрудникам больше возможности применять свои знания [38]. А фирмам смело применять эти знания для внедрения инноваций. В таком контексте сотрудников поощряют реализовывать потенциальную ценность своего человеческого капитала.

Таким образом, можно сделать следующие выводы.

Во-первых, руководителям стоит уделять большее внимание развитию трудового потенциала, тем самым получая человеческий капитал внутри фирмы. Сосредоточение внимания на внутреннем развитии человеческого капитала, более эффективно влияет на инновационные цели фирмы.

Во-вторых, менеджерам следует эффективно использовать человеческий капитал, через обучение по конкретным задачам, и разрабатывать политику, поощряющую участие сотрудников.

Использование готового человеческого капитал недостаточно для развития, так как ценность сотрудников может быть утеряна в процессе управления трудовым потенциалом. Предприятия должны развивать трудовой потенциал внутри фирмы, и тем самым реализовать человеческий капитал. 


\section{Библиографический список}

1. Виноградова, В.Ю. К определению понятий «человеческий, социальный и интеллектуальный капитал» / В.Б.Виноградова // Изменяющаяся Россия. Социально-экономические инновации: материалы XXV международной научно-практической конференции / Урал.соц-экон. ин-т АТиСО. - Челябинск, 2008. - Ч. II. С.50.

2. Власова, В.И. Трудовые ресурсы и их использование в условиях инновационной экономики региона // Наука, образование и культура. - № 8 (23). - 2017. - С. 17.

3. Генкин, Б. М. Экономика и социология труда. / Б. М. Генкин. - 2-е изд., испр и доп. - М.: НОРМА: 1999.

4. Генкин Б. М. Экономика и социология труда. М.: 7-е издание, дополненное, Изд. Норма, 2007. -С. 43-71

5. Даниловских, Т. Е. Методики оценки человеческого капитала: подходы к классификации / Т. Е. Даниловских, А. Г. Авакян //Фундаментальные исследования. - 2015. - № 6-1. - С. 108-111.

6. Добрынин, А.И. Человеческий капитал в транзитивной экономике: формирование, оценка эффективность использования /А.И. Добрынин, С.А. Дятлов, Е. Д. Цыренова. - СПб.: Наука, 1999. -309 с.

7. Дятлов, С. А. Основы теории человеческого капитала / С.А.Дятлов. - СПб., 1994. - С.76.

8. Ильинский, И. В. Инвестиции в будущее: образование в инновационном воспроизводстве / И. В. Ильинский. СПб.: Изд. СПбУЭФ, 1996.

9. Климов, С. М. Интеллектуальные ресурсы организации. СПб: ИВЭСЭП, «Знание», 2000. - 167 с.

10. Корогодин, И. Социально-трудовая система: вопросы методологиии теории / монография. М.: ПАЛЕОТИН, 2005. - $221 \mathrm{c}$.

11. Костюк, В.И. Теория эволюции и социоэкономические процессы. М.: Едиториал УРсс, 2004. - 176 с. $120-$ 121.

12. Критский, М. М. Человеческий капитал / М. М. Критский. -Л.: Изд-во Ленингр. ун-та, 1991.

13. Лифшиц А.С. Управление человеческими ресурсами: теория и практика: учеб. пособие / А. С.Лифшиц. М.: РИОР: ИНФРА-М, 2019. - 266 с.

14. Маслоу, А. Новые рубежи человеческой природы / пер. с англ. - М.: Смысл. 1999.- 425 с.

15. Мустафин А.Н. Состояние и развитие человеческого капитала инновационно-активных предприятийдиссертация на соискание ученой степени кандидата экономических наук 2018 г.

16. Мясоедова, Т.Г. Человеческий капитал и конкурентоспособность предприятия / Т. Г. Мясоедова // Менеджмент в России и за рубежом. - 2005. № 3. С. 29-37.

17. Наумова, Е.Ю., Сидунова, Г.И. Состав трудового потенциала на разных экономических уровнях // Известия ВГПУ, 2012. - С. 135.

18. Никитина, И.А. Концепция человеческого капитала в системе управления персоналом на российском предприятии / И.А. Никитина. - СПб., 1999. - С.22-24.

19. Плячкайтене, И. М. Становление и развитие теории человеческого капитала / И. М. Плячкайтене // Молодой ученый. - 2011. -№ 7. - С. 102-104.

20. Сафиуллин Л.Н., Мингазова А.Ф. Влияние состояния здоровья трудоспособного населения страны на эффективность инновационного развития российской экономики. // Казанский экономический вестник». 2019. № 1 (39) С. 71-77. ISSN 2305-4212

21. Сафиуллин Л. Н., Мингазова А. Ф. Биофизический капитал в условиях развития современной экономики // Экономика и предпринимательство, № 11, 2018 г С.62-66.

22. Сочнева, E.H. Человеческий капитал: проблемы измерения и роста в российской экономике: монография / Е. Н. Сочнева. - Красноярск: Сиб. федер. ун-т, 2016. - 190 с. С 2-8.

23. Стукач, Ф.В. Формирование и оценка базового человеческого капитала сельского хозяйства / Ф.В.Стукач, Е. Ю. Лалова //Омский научный вестник. - 2012. - № 4. - С. 111.

24. Фахрутдинова Е. В. Человеческий капитал в Республике Татарстан: динамика развития/ Вопросы экономики и права. - 2013. - № 66. - С.121-124.

25. Фахрутдинова Е.В. Рынок труда в России и динамика его потребностей// Экономические науки. 2014. № 110. - C.43-46.

26. Фахрутдинова Е. В. Диалектика потребностей человека// Экономические науки. 2009. - № 57. -С.43-47.

27. Шуняев, А. В. Тенденции изменения качества рабочей силы как основы ее конкурентоспособности в современной экономике // Интернет-журнал «НАУКОВЕДЕНИЕ». - т.7. - № 3. - 2015 [Электронный ресурс]. Режим доступа: https://naukovedenie.ru/PDF/67EVN315.pdf

28. Becker Gary S. Human Capital. N. Y.: Columbia University Press, 1964. 
29. Chatterjee J. Strategy, human capital investments, business-domain capabilities, and performance: a study in theglobal software services industry Strat. Manag. J., 38 (7) (2017), pp. 588-608

30. Chadwick C., Super J.F., Kwon K Resource orchestration in practice: CEO emphasis on SHRM, commitment-based HR Strat. Manag. J., 36 (3) (2015), pp. 360-376.

31. Fakhrutdinova E., Severyanov O., Shigabutdinov A., Fakhrutdinov R. The crisis of 1988 in Russia: political intervention and its implication// Life Science Journal. 2014. T. 11. № 6s. C. 442-447.

32. Morrison E. W. Employee voice behavior: integration and directions for future research Acad. Manag. Ann., 5 (2011), pp. 373-412

33. Wang L., Yeung J. H.Y., Zhang $M$ The impact of trust and contract on innovation performance: the moderating role of environmental uncertainty Int. J. Prod. Econ., 134 (2011), pp. 114-122

34. Vuori T.O., Huy Q. N. Distributed attention and shared emotions in the innovation process: how Nokia lost the smartphone battle Adm. Sci. Q., 61 (1) (2016), pp. 9-51

35. Zeng J., Zhang $W$., Matsui $Y$., Zhao $X$. The impact of organizational context on hard and soft quality management and innovation performance Int. J.Prod. Econ., 185 (2017), pp. 240-251

36. https://www.worldbank.org/

37. Маршал А. Принципы экономической науки URL: http://www.finansy.ru /books/macro002/004.htm (дата обращения 15.10.2017)

38. C. Katsikeas, C.Leonidou, A.Zeriti Eco-friendly product development strategy: antecedents, outcomes, and contingent effectsJ. Acad. Market. Sci., 44 (6) (2016), pp 